\title{
Discussion on the Relationship between Dieting and Bone Density among Female College Students and the Health Guidance
}

\section{Fumihiro Omasu ${ }^{1 *}$, Kotomi Aishima², Mio Nasu², Youhei Hisatsugu², Keika Fuchigami², Tomomi Gotoh ${ }^{2}$}

\author{
${ }^{1}$ Department of Health and Nutrition, Faculty of Health and Nutrition, Yamagata Prefectural Yonezawa University of Nutrition \\ Sciences, Yonezawa, Japan \\ ${ }^{2}$ Department of School Health, Faculty of Education, Kumamoto University, Kumamoto, Japan \\ Email: *omasu@yone.ac.jp
}

How to cite this paper: Omasu, F., Aishima, K., Nasu, M., Hisatsugu, Y., Fuchigami, K. and Gotoh, T. (2019) Discussion on the Relationship between Dieting and Bone Density among Female College Students and the Health Guidance. Open Journal of Preventive Medicine, 9, 11-19.

https://doi.org/10.4236/ojpm.2019.92002

Received: January 20, 2019

Accepted: February 25, 2019

Published: February 28, 2019

Copyright $\odot 2019$ by author(s) and Scientific Research Publishing Inc. This work is licensed under the Creative Commons Attribution International License (CC BY 4.0).

http://creativecommons.org/licenses/by/4.0/

(c) (i) Open Access

\begin{abstract}
We studied the relationship between dieting and bone density among female college students and the current state thereof. Female college students are generally thin, with the time to giving birth and raising the next generation approaching. We expect the results of this study will be useful in improving health guidance. The subjects consisted of 124 female college students. Their average age was 21.4. The ultrasonic propagation velocity of the heel bone was measured as the bone density value. Body height, weight, and BMI (Body mass index) were also measured. Further, a multiple choice and short answer survey was conducted regarding their desire to be thin and dieting. Classifying the subjects by BMI, 16 students were underweight (13\%), 102 students were of normal weight (84\%), and 4 students were overweight (3\%). $95 \%$ of those in the normal weight group had a desire to be thin, while $44 \%$ of the underweight group had a desire to be thin. Moreover, $31 \%$ of those in the normal weight group were currently on a diet, while $21 \%$ of the underweight group was also on a diet. The distribution of bone density (\%YAM value: Young Adult Mean) was as follows: 61 students (49\%) were in the high density group ( $\geq 100)$; 58 students $(47 \%)$ were in the middle density group $(\geq 80$ $<100)$; and 5 students $(4 \%)$ were in the low density group $(<80)$. The more the bone density decreased, the greater the proportion of students with dieting experience. Among students with no dieting experience, the \%YAM value was high when the BMI value was high. All of the students in the low density group had a desire to be thin, even though their bone density was low. Students who do not need to be thin had a desire to be thin and were considering continuing dieting going forward. Moreover, some students fell into the \%YAM low density group, which is worrisome for the future. It is be-
\end{abstract}


lieved necessary to reinforce health guidance regarding dieting and bone density in school education. In particular, it is necessary to improve guidance since we observed a lack of knowledge regarding osteoporosis prevention.

\section{Keywords}

Body Mass Index, Desire to Be Thin, Dieting, Bone Density, Female College Student

\section{Introduction}

In recent years, there has been an increasing tendency among young females to be thin [1]. If losing weight becomes more serious, it may lead to ovarian insufficiencies such as irregular menstruation and amenorrhea, along with physical symptoms such as osteoporosis, anemia, and hair loss. It may also lead to diseases such as anorexia nervosa [2]. This problem regarding body thinness is now appearing in those of a younger age than ever [3]. Losing weight in an unhealthy way (when the growth curve of weight is downward crossing for one channel or more) is significantly increasing among females in junior high school and high school [4] [5].

Although studies on the relationship between eating behaviors, self-esteem and the desire to be thin can be found in previous studies [6] [7] [8], there are few studies on how these distorted perceived body shapes, that can be considered to be a cause of the desire to be thin, affect the bone density.

Therefore, school nurses have to provide students with adequate health guidance. We studied the relation between dieting and bone density among female college students and the current state thereof. They are generally thin, with the time to giving birth and raising the next generation approaching. We expect the results of this study will be useful in improving health guidance.

\section{Methods}

The subjects consisted of 124 female college students. A sufficient number of subjects and average female college students were sorted out from this study in line with other similar studies [9] [10]. Their average age was 21.4. All data in the present study were collected in November 2017 at a university in the middle area of Kyusyu. Each of the participants lived in the area surrounding the university. Females with a history of treatment or therapy that might have influenced their bone mass were excluded. The study was approved by the Ethics Committee of Epidemiological Studies at Yamagata Prefectural Yonezawa University of Nutrition Sciences.

Since we were conducting a survey having to do with physical condition, we were careful in regards to privacy. Specifically, we explained to students that the answers and test results would be anonymous when statistically processed and 
that the information would not be shared to third parties, with students who gave their consent used as subjects.

The ultrasonic propagation velocity of the heel bone, SOS $(\mathrm{m} / \mathrm{sec}$ ) (Speed of Sound), was measured by ultrasound using a bone densitometry device (CM-200 from Canon). Moreover, we compared the current bone density (\%) of the students by setting the average bone density of healthy females from $20-44$ years old as $100 \%$, then calculated the \%YAM (Young Adult Mean) value in order to use the results for all analyses below. Body height, weight, and BMI (Body mass index) were also measured when measuring the ultrasonic propagation velocity of the heel bone. The survey items were as follows: attitude towards dieting; dieting experience; current situation regarding dieting; and surrounding people who are on a diet.

In the analysis of this study, we measured the data of the survey results with a level of significance of $5 \%$. As for the method of statistical analysis, we used a chi-squared test along with calculation of the correlation function and analysis thereof.

\section{Results}

Table 1 shows the physical characteristics of the subjects. The mean age was 21.4 \pm 3.2 (range: 20 - 44 years). The average height of the subjects was $158.1 \pm 5.5$ $\mathrm{cm}$. The average weight of the subjects was $51.8 \pm 6.9 \mathrm{~kg}$. The average BMI was $20.8 \pm 2.3 \mathrm{~kg} / \mathrm{m}^{2}$. The average bone density (SOS value) was $1538.8 \pm 29.3 \mathrm{~m} / \mathrm{sec}$, while the average bone density (\%YAM value) was $100.6 \% \pm 16.1 \%$.

BMI was categorized into three groups in accordance with the value thereof: an "underweight group" for less than 18.5; a "normal weight group" for 18.5 or more and less than 25; and an "overweight group" for 25 or more [9]. The distribution of the subjects was as follows: 16 students were in the underweight group (13\%); 102 students were in the normal weight group (84\%); and 4 students were in the overweight group (3\%) (Table 2).

Bone density (\%YAM value) was classified into three groups: a low density group $(<80)$; a middle density group $(\geq 80-<100)$; and a high density group $(\geq 100)$ [9]. The distribution of the subjects was as follows: 5 students in the low density group (4\%); 58 students in the middle density group (47\%); and 61 students in the high density group (49\%) (Table 3 ).

Analyzing the relation between each BMI group and bone density, it was found that $50 \%$ of those in the overweight group were in the high density group, while the other $50 \%$ were in the middle density group, with no one in the overweight group in the low density group (Table 4). Regarding the normal weight group and underweight group, the high density group and the middle density group added up to $90 \%$ or more. However, those in the low density group were observed in both groups, with $4 \%$ in the normal weight group and $6 \%$ in the underweight group. The results of the chi-squared test to see if there is a relation between BMI groups and bone density indicated no significant difference.

Analyzing the relationship between BMI and the desire to be thin, it was 
found that $90 \%$ or more of those in the normal weight group had a desire to be thin (Table 5). Moreover, among students in the underweight group, $44 \%$ of them had a desire to be thinner despite the fact that they were already in the underweight group. The results of the chi-squared test to see if there is a relation between the BMI groups and the presence of the desire to be thin indicated a significant difference $(\mathrm{p}<0.01)$.

Analyzing the relationship between the presence of the desire to be thin and bone density, it was found that 53 students in the high density group had a desire to be thin $(87 \%)$, while 52 students in the middle density group had a desire to be thin (89\%) (Table 6). Moreover, 5 students in the low density group had a desire to be thin $(100 \%)$. The results of the chi-squared test to see if there is a relation between the bone density groups and the presence of the desire to be thin indicated no significant difference.

67 students had dieting experience (54\%), while 57 students had no dieting experience (46\%) (Table 7). Analyzing BMI and the presence of dieting experience, in the underweight group, it was found that 5 students had dieting experience (31\%), while 11 students had no dieting experience (69\%). In the normal weight group, 59 students had dieting experience (57\%), while 45 students had no dieting experience (43\%). In the overweight group, 3 students had dieting experience (75\%), while 1 student had no dieting experience (25\%). The results of chi-squared test to see if there is a relation between BMI groups and the presence of dieting experience indicated a significant difference $(\mathrm{p}<0.01)$.

We analyzed the relationship between the presence of dieting experience and bone density. In the high density group, 29 students had no dieting experience (48\%), while 32 students had dieting experience (52\%) (Table 8). In the middle density group, 27 students had no dieting experience (47\%), while 31 students had dieting experience (53\%). All students in the low density group had dieting experience, meaning 5 students had experience (100\%).

We calculated the correlation coefficient and analyzed it in order to see the correlation between BMI and bone density. The correlation coefficient in the group of students with dieting experience was $r=-0.051$, meaning there was no correlation. The correlation coefficient in the group of students with no dieting experience was $r=0.217$, demonstrating a significant positive correlation $(\mathrm{p}<$ $0.05)$.

Table 1. Physical characteristics of the subjects.

\begin{tabular}{cc}
\hline Number of people (persons) & 124 \\
\hline Age (years) & $21.4 \pm 3.2$ \\
Height $(\mathrm{cm})$ & $158.1 \pm 5.5$ \\
Weight $(\mathrm{kg})$ & $51.8 \pm 6.9$ \\
BMI (Body Mass Index) $\left(\mathrm{kg} / \mathrm{m}^{2}\right)$ & $20.8 \pm 2.3$ \\
\%YAM (Young Adult Mean) $(\%)$ & $100.6 \pm 16.1$ \\
SOS (Speed of Sound) $(\mathrm{m} / \mathrm{sec})$ & $1538.8 \pm 29.3$
\end{tabular}


Table 2. The number of students and percentage by BMI group.

\begin{tabular}{cccc}
\hline & Underweight $(<18.5)$ & Normal weight $(\geq 18.5-<25)$ & Overweight $(\geq 25)$ \\
\hline \multirow{2}{*}{ BMI Group } & 16 students & 104 students & 4 students \\
& $13 \%$ & $84 \%$ & $3 \%$ \\
\hline
\end{tabular}

Table 3. The number of students and percentage by bone density (\%YAM value).

\begin{tabular}{cccc}
\hline & $\begin{array}{c}\text { Low density } \\
(<80)\end{array}$ & $\begin{array}{c}\text { Middle density } \\
(\geq 80-<100)\end{array}$ & $\begin{array}{c}\text { High density } \\
(\geq 100)\end{array}$ \\
\hline $\begin{array}{c}\text { Bone density (\%YAM } \\
\text { value) group }\end{array}$ & $\begin{array}{c}5 \text { students } \\
4 \%\end{array}$ & $\begin{array}{c}58 \text { students } \\
4 \%\end{array}$ & $\begin{array}{c}61 \text { students } \\
49 \%\end{array}$ \\
\hline
\end{tabular}

Table 4. The number of students and the percentage of the number of students by BMI groups classified by bone density (\%YAM value).

\begin{tabular}{cccc}
\hline Bone density & Low density & Middle density & High density \\
(\% YM value) group & 5 students & 58 students & 61 students \\
BMI Group & 1 student & 8 students & 7 students \\
Underweight & $6 \%$ & $50 \%$ & $44 \%$ \\
16 students & 4 students & 48 students & 52 students \\
Normal weight & $4 \%$ & $46 \%$ & $50 \%$ \\
104 students & 0 students & 2 students & $50 \%$ \\
Overweight & $0 \%$ & $50 \%$ \\
4 students & & & 2 students \\
\hline
\end{tabular}

Table 5. The number of students and the percentage of the number of students by BMI groups classified by the presence of the desire to be thin.

\begin{tabular}{ccc}
\hline BMI Group & $\begin{array}{c}\text { Have a desire to be thin } 110 \\
\text { students } 89 \%\end{array}$ & $\begin{array}{c}\text { Have no desire to be thin } 14 \\
\text { students } 11 \%\end{array}$ \\
\hline Underweight 16 students & 7 students & 9 students \\
Normal weight 104 students & $94 \%$ & $56 \%$ \\
& $95 \%$ & 5 students \\
Overweight 4 students & 4 students & $5 \%$ \\
& $100 \%$ & 0 students \\
\end{tabular}

Table 6. The number of students and the percentage of the number of students by bone density (\%YAM value) groups classified by the presence of the desire to be thin.

\begin{tabular}{ccc}
\hline $\begin{array}{c}\text { Bone density (\%YAM value) } \\
\text { group }\end{array}$ & $\begin{array}{c}\text { Have a desire to be thin } 110 \\
\text { students } 89 \%\end{array}$ & $\begin{array}{c}\text { Have no desire to be thin } 14 \\
\text { students } 11 \%\end{array}$ \\
\hline $\begin{array}{c}\text { High density } \\
61 \text { students }\end{array}$ & 53 students \\
Middle density & 52 students & 8 students \\
58 students & $89 \%$ & 6 students \\
Low density & 5 students \\
5 students & $100 \%$ & 0 students \\
\end{tabular}


Table 7. The number of students and the percentage of the number of students by BMI groups classified by the presence of dieting experience.

\begin{tabular}{ccc}
\hline BMI Group & $\begin{array}{c}\text { Have dieting experience 67 } \\
\text { students 54\% }\end{array}$ & $\begin{array}{c}\text { Have no dieting experience 57 } \\
\text { students 46\% }\end{array}$ \\
\hline Underweight 16 students & 5 students & 11 students \\
& $31 \%$ & $69 \%$ \\
Normal weight 104 students & 59 students & 45 students \\
Overweight 4 students & $57 \%$ & $43 \%$ \\
& 3 students & 1 student \\
\hline
\end{tabular}

Table 8. The number of students and the percentage of the number of students by bone density (\%YAM value) classified by the presence of dieting experience.

\begin{tabular}{ccc}
\hline $\begin{array}{c}\text { Bone density } \\
\text { (\%YAM value) group }\end{array}$ & $\begin{array}{c}\text { Have dieting experience } 67 \\
\text { students } 54 \%\end{array}$ & $\begin{array}{c}\text { Have no dieting experience } 57 \\
\text { students } 46 \%\end{array}$ \\
\hline High density & 32 students & 29 students \\
61 students & $52 \%$ & $48 \%$ \\
Middle density & 30 students & 28 students \\
58 students & $52 \%$ & $48 \%$ \\
Low density & 5 students & 0 students \\
5 students & $100 \%$ & $0 \%$ \\
\hline
\end{tabular}

\section{Discussion}

There was a tendency towards less underweight students and more normal weight students among the female college students participating in our study. However, they tended to misunderstand their self evaluation regarding their bodies. $95 \%$ of those in the normal weight group had a desire to be thin, while $44 \%$ of the underweight group had a desire to be thin. Moreover, more than half of the students had dieting experience, with $31 \%$ of those in the normal weight group and $21 \%$ of those in the underweight group currently on a diet. In other words, we found a tendency for the number of students with dieting experience to increase as the BMI value rises [9] [10]. However, there is a concern regarding being extremely underweight since the percentage of students in the underweight group with dieting experience reached up to $31 \%$. In addition, the frequency of conversations regarding losing weight was higher in the underweight group and normal weight group, despite there being no need for them to lose weight. Therefore, it is thought that students who do not need to be thin had a desire to be thin, meaning they will potentially continue to go on a diet. The media, influence from their surroundings such as families and friends, and a decline in self-esteem are the factors that influence them to take these actions of losing weight and impact their body image [11] [12]. The influence of information, recognition, and images that the media provides people is believed to be huge. Information magazines, radio, and TV that emphasize "slimness" may force females to lose weight and provoke restrictions on their diet in order to gain 
self-satisfaction and a more beautiful appearance [13]. Therefore, the desire to be thin is thought to be influenced by the slim bodies that appear on TV and in magazines. Among individuals with dieting experience, in a survey regarding their motives when they first decided to go on a diet, it was found that $27 \%$ of them started to lose weight due to the influence of those by whom they were surrounded. Thus, it can be said that the influence of those surrounding them, such as family members and friends, is huge. Moreover, it can also be said that some people start to go on diets because their evaluations of their own bodies are low, in other words, they have low self-esteem of their own bodies.

There are several limitations associated with the present study. First, the number of subjects was small. Therefore, larger studies are needed in order to obtain more detailed information regarding bone density in the future. Second, the questionnaire used in this study is one that addresses self-perceived bone health. In the future, it will be necessary to collect more in-depth information.

It is necessary to provide health guidance that allows them to correctly understand their own bodies in the growth phase. If they go on a diet due to wrongly understanding their own bodies, this may lead to harmful effects such as osteoporosis and amenorrhea [14] [15]. The age of the subjects was the age when their bone density is the highest in their lives, thus a bone density of $<80$ at their age may come with a risk of osteoporosis in the future. As a result of this study, we found that as bone density gets lower, the percentage of students with dieting experience increases. Among the subjects with no dieting experience, we found a tendency for the bone density to be higher as the BMI value increased. In addition, since all of the students in the low density group had a desire to be thin despite the fact that their bone density was low, osteoporosis in the future is of concern with a decline in BMI starting from dieting embodied by their desire to be thin.

It can be said that female college students go on a diet mostly by restricting their diets. However, previous studies reported that dieting only by dietary restrictions may lead to eating disorders, along with the fact that the body fat percentage is higher in individuals with no dieting experience, since dietary restrictions do not affect reductions in body fat [16]. Moreover, dieting only by dietary restrictions leads to a failure to intake necessary nutrition and comes with a risk of losing muscle mass along with a high possibility of regaining weight [17]. Upon conducting an analysis regarding regaining weight by comparing the regaining proportion of subjects who lost less than $1 \mathrm{~kg}$ in one week and the proportion of subjects who lost more than $1 \mathrm{~kg}$ in one week, we observed a significant difference (data not shown). This indicates that the possibility of regaining weight increases when losing more than $1 \mathrm{~kg}$ in one week by dieting.

It is important to reinforce healing guidance among female college students in their secondary growth phase while they are able to gain maximum bone mass and their body shapes change drastically. Furthermore, upon conducting a survey to see if the subjects have basic knowledge on bone density, we observed a 
lack of knowledge, with approximately $20 \%$ of students giving all correct answers (data not shown). Given that, it is believed necessary to reinforce health guidance regarding dieting and bone density in school education. When providing health guidance regarding dieting and bone density in schools, it is believed important to do so not via a school nurse alone but with a nutrition educator and P.E. teacher. A well-balanced diet and moderate exercise are essential for osteoporosis prevention. By cooperating with a nutrition educator and P.E. Teacher who have technical knowledge in these fields, it is possible to provide better health guidance.

\section{Conclusion}

This time, we conducted a survey regarding the relationship between dieting and bone density among female college students and the current state thereof. While many of the subjects had a desire to be thin, many of them did not need to be thin. We found that even now, subjects who do not need to be thin continue to remain on a diet, with some dieting in an extreme way. Therefore, 1) Maintain a regular lifestyle, eating three meals a day without skipping. 2) Try to make energy consumption supersede energy intake. 3) Eat good balanced meals without being picky. 4) Eat a variety of food, not only particular foods. 5) Eat slowly and chew well. 6) Combine diet and exercise. 7) Do not set strict goals, but lose weight over longer periods. 8) Learn the influence on bones and bone structure when dieting. 9) Learn the phase when bone mass can be acquired most, along with long-term changes in bone density. 10) Learn necessary diet and exercise to prevent osteoporosis. Students should be instructed on these 10 items. In addition, it is necessary to cooperate with a nutrition educator and P.E. teacher with technical knowledge in the fields of diet and exercise in order to provide better health guidance.

\section{Conflicts of Interest}

The authors declare no conflicts of interest regarding the publication of this paper.

\section{References}

[1] Omasu, F. and Hayashi, M. (2013) The Effect of Perceived Body Shapes on the Desireto Bethin in Fifth and Sixth Graders in Elementary School. Asian Pacific Journal of Disease Management, 7, 25-33. https://doi.org/10.7223/apjdm.7.25

[2] Smith, A.R., Joiner Jr., T.E. and Dodd, D.R. (2014) Examining Implicit Attitudes toward Emaciation and Thinness in Anorexia Nervosa. International Journal of Eating Disorders, 47, 138-147. https://doi.org/10.1002/eat.22210

[3] Matsuura, K. (2000) A Study on the Preference for Thinness among Female Primary-School Children. The Journal of Child Health, 59, 532-539. (In Japanese)

[4] Kaneda, F., Sugano, S., Sano, A., Nishida, M., Yoshiike, N. and Yamamoto, S. (2004) Systematic Review of the Frequency of "Thinness" among Children and Adolescents in Japan. The Japanese Society of Nutrition and Dietetics, 62, 347-360. 
https://doi.org/10.5264/eiyogakuzashi.62.347

[5] Berkowitz, S.A., Wit, A.A., Gillberg, C., Råstam, M., Wentz, E. and Lowe, M.R. (2016) Childhood Body Mass Index in Adolescent-Onset Anorexia Nervosa. International Journal of Eating Disorders, 49, 1002-1009. https://doi.org/10.1002/eat.22584

[6] Ogino, T., Hasui, R., Hosoda, A. and Yamamoto, Y. (2006) Surveyon Desire to Be Slim, Consciousness of Body Image and Past Dieting Experience of Young Females. Journal of Human Life Science, 5, 25-33. (In Japanese)

[7] Takeuchi, S., Hayano, J., Hori, R. and Mukai, S. (1993) Body Image and Self Image (2nd Report): Low Self-Esteem and Over-Estimation of Body Weight. Japanese Journal of Psychosomatic Medicine, 33, 697-703. (In Japanese)

[8] Tagawa, M., Nishikawa, T., Arashima, S. and Okayasu, T. (2000) The Relationship between Body Perception and Self-Esteem. Japanese Journal of School Health, 42, 413-422. (In Japanese)

[9] Omasu, F., Murakami, K., Fukuda, M. and Gotoh, T. (2018) The Influence of over Dieting on Bone Density in Japanese Female University Students. International Journal of Clinical Medicine Research, 5, 67-71.

[10] Omasu, F., Umemoto, M., Gotanda, R. and Gotoh, T. (2017) Effect That Lifestyle during the Growth Period Has on Bone Density Acquisition-Using Simple Exercise and a Nutrition Survey. Open Journal of Preventive Medicine, 7, 87-97. https://doi.org/10.4236/ojpm.2017.75008

[11] Herbozo, S., Tantleff-Dunn, S., Gokee-Larose, J. and Thompson, J.K. (2004) Beauty and Thinness Messages in Children's Media: A Content Analysis. Eating Disorders, 12, 21-34. https://doi.org/10.1080/10640260490267742

[12] Naeimi, A.F., Haghighian, H.K., Gargari, B.P., Alizadeh, M. and Rouzitalab, T. (2016) Eating Disorders Risk and Its Relation to Self-Esteem and Body Image in Iranian University Students of Medical Sciences. Eating and Weight Disorders, 21, 597-605. https://doi.org/10.1007/s40519-016-0283-7

[13] Imai, K., Masuda, T. and Komiya, S. (1994) Actual State of Misconception Regarding Physique and Desire for Slenderness in Female Adolescents. The Japanese Journal of Nutrition and Dietetics, 52, 75-82. (In Japanese)

[14] Komura, H. (2009) The Management of Eating Disorder in Adolescence. Obstetrical and Gynecological Therapy, 99, 611-616. (In Japanese)

[15] Omasu, F., Seki, Y., Hashiguchi, S., Hashiguchi, S., Yamakami, K., Sakurai, Y. and Nakahara, Y. (2011) The Influence of Physical Activity on the Bone Mass through the Bone Metabolism in Premenopausal Adult Japanese Women. Journal of Public Health, 19, 241-247. https://doi.org/10.1007/s10389-011-0394-6

[16] Nonaka, M. (2015) Survey on Body Perception and Lifestyle Habits of High School Students. Journal of Home Economics of Japan, 66, 342-350. (In Japanese)

[17] Miyachi, M. (2008) Instruction Regarding Exercise and Physical Activities for Specific Medical Checkups and Health Guidance. Japanese Journal of Complementary and Alternative Medicine, 5, 115-122. (In Japanese) 